\title{
Effects of land use on soil saturated hydraulic conductivity of Horqin Sand Land
}

\author{
S.X. YAO ${ }^{1,2}$, C.C. ZHAO ${ }^{1,2}$, X.M. ZHAO ${ }^{3}$, S.Y. WANG ${ }^{1}$, Y.J. LI ${ }^{1}$, L.N. TIAN ${ }^{1}$ \\ 1. Lanzhou City University, Lanzhou 730070, China; \\ 2.Cold and Arid Regions of Environmental and Engineering Research Institute, Chinese Academy \\ of Sciences, Lanzhou 730000, China;
}

\section{Department of Basic Courses, Lanzhou Institute of Technology, Lanzhou 730000, China}

KEYWORD: Saturated hydraulic conductivity, Land use, Horqin Sand Land

ABSTRACT: In order to analyze the influence of land use on soil saturated hydraulic conductivity $(K f s)$, three typical sandy lands of Horqin Sand Land were chosen, including pine woodland, poplar woodland and farmland, and three fields for each type to identified for $K f s$ measurement. The $K f s$ of five soil depths $(0 \sim 20 \mathrm{~cm}, 20 \sim 40 \mathrm{~cm}, 40 \sim 60 \mathrm{~cm}, 60 \sim 80 \mathrm{~cm}$ and $80 \sim 100 \mathrm{~cm})$ at each field was measured in situ by Guelph Permeameter. The relationship of $K f s$ with sand types, soil depths, and soil physiochemical properties were analyzed. The results showed that (1) The averaged $K f s$ was decreased in the order: pine woodland > poplar woodland > farmland, with averaged value was 3.99, 2.60 and $0.93 \mathrm{~mm} / \mathrm{min}$, that was, $K f s$ of Horqin Sand Land was largely influenced by land use. (2) The trend in $K f s$ with increasing soil depth was not consistent among the type of sand land, e.g., the changes of $K f s$ along with soil depth in pine woodland was fitted by parabola model, but there was no law for poplar woodland and farmland. (3) The relationships of $K f s$ and soil physiochemical property revealed that soil organic matter content and mechanical components were the key factors affecting $K f s$ of Horqin Sand Land, next was soil bulk density, and $K f s$ increased with increasing coarse sand fraction $(2 \sim 0.1 \mathrm{~mm})$ and bulk density, but $K f s$ decreased with increasing soil clay and silt content proportion (that was $0.1 \sim 0.05 \mathrm{~mm}$ and $<0.05 \mathrm{~mm}$, respectively), and organic matter content.

\section{INTRODUCTION}

Soil saturated hydraulic conductivity $(K f s)$ refers to the amount of water passing through unit area in unit time under unit water potential gradient when the soil is water-saturated. It can be used to reflect the infiltration and seepage properties of soil, and serve as an important parameter for studying the moisture and solute transport, speculating the soil non-saturated hydraulic conductivity, calculating the soil profile water flux, and designing irrigation drainage system projects (Fares et al. 2000). In the meanwhile, the $K f s$ is an important parameter in the study of water balance, which affects the distribution relationship among ground water infiltration, runoff and evapotranspiration (Zheng et al. 2004). It is influenced by many factors, such as soil moisture characteristics, soil texture, structure, organic matter content and land use pattern (Hu et al. 2005). Therefore, the $K f s$ has a high degree of spatial variability, and such spatial variability is used as an important factor in the water distribution relationship of the ecological system (Niu et al. 1999). The development and utilization of the sandy land as an important land resource has attracted high attention. Water is a dominant factor in sandy habitats, and the study of its parameters is conducive for understanding the dynamic characteristics of soil moisture, thereby laying a foundation for research on the water consumption patterns of plants under natural conditions and water cycle characteristics ( $\mathrm{Su}$. 2000). At present, studies on $K f s$ mostly focus on the determination method (Amoozegar. 1989), model prediction (Tietje \& Hennings, 1996), spatial heterogeneity of top Kfs (Zhao et al. 2009) and other aspects. However, there are not many comparisons of and studies on sandy $K f s$ under different land use patterns (Liang et al. 2009; Price et al. 2010). Among them, there are many methods available for the determination of $K f s$, such as double ring method, parameter method and soil column method. Guelph infiltrometer (Guelph Permeator, 2008KI, Santa Barbara, CA93105, U. S. A.) is a portable infiltration device for in situ determination of $K f s$ by using the principle of steady 
water-head infiltration (Yao et al. 2013(a)). In view of this, with Horqin Sandy Land, one of China's largest four sandy lands, as the study area and relying on Naiman Station for Desertification Experiment and Research of the Chinese Ecosystem Research Network, this study selected sandy lands of three land use patterns (pine woodland, poplar woodland and farmland) as the objects of study, and applied Guelph infiltrometer to study the change patterns of $K f s$ at different soil layers (every $20 \mathrm{~cm}$ was a new soil layer, and the lower limits of soil layer were respectively $20 \mathrm{~cm}, 40 \mathrm{~cm}$, $60 \mathrm{~cm}, 80 \mathrm{~cm}$ and $100 \mathrm{~cm}$ ) of these three types of sandy land and their relationship with the land use type so as to provide certain guidance and a theoretical basis for research on vegetation construction, ecological restoration and soil and water conservation in this region.

\section{MATERIAL AND METHODS}

\section{Study site description}

The study sites located at Naiman County in southwestern of Horqin Sand Land, North China. At the region, the $40-\mathrm{yr}$ annual mean precipitation was $360 \mathrm{~mm}, 75 \%$ of which is received from June to September, and the annual mean potential evaporation is $1991 \mathrm{~mm}$. The 40-yr annual mean temperature is around $6.4^{\circ} \mathrm{C}$, with the minimum monthly mean temperature of $-13.1^{\circ} \mathrm{C}$ in January and the maximum $23.7^{\circ} \mathrm{C}$ in July. The annual mean wind velocity is in the range of $3.2 \sim 4.1 \mathrm{~m} \mathrm{~s}^{-1}$. The soil, with loose sand and low content of organic matter, is vulnerable to wind erosion and aeolian soil which degraded from sandy chestnut soil (Yao et al. 2013(b)).

\section{Study method}

\section{Site choosing}

Three typical sites were selected for measurement of $K f s$ from Naiman County in this study, including pine woodland, hereinafter, for PNW, poplar woodland for PW and farmland for FL. There were three fields with similar settings each other as three replications for each site. On each field, 15 sample points spaced 5 meters apart were selected, a total of 135 sample points.

Soil sampling and soil properties determining

A soil profile with $1 \mathrm{~m}$ depth near to the $K f s$ measuring points (that was, sample point) was dug for each field. Three undisturbed soil samples for each layer were taken on the profile at interval with $20 \mathrm{~cm}$ using a cylindrical metal core with a height of $5 \mathrm{~cm}$ and a volume of $100 \mathrm{~cm}^{3}$. The soil bulk density was first measured using volume-mass relationship and then the same soil sample was used to determine other basic soil properties. The soil organic matter content was determined using the $\mathrm{K}_{2} \mathrm{Cr}_{2} \mathrm{O}_{7}-\mathrm{H}_{2} \mathrm{SO}_{4}$ wet oxidation method (Institute of Soil Sciences, 1978). The soil particle size distribution was determined by dry sieving method. Each soil properties were all the average of three replicates for each field.

\section{Measured of Kfs}

$K f s$ was calculated as follows function through inputting the parameter value of $\mathrm{R}_{1}$ and $\mathrm{R}_{2}$ which were determined in situ by Guelph Prememeater under constant water head at $5 \mathrm{~cm}$ and $10 \mathrm{~cm}$, respectively. We measure 5 layers from surface to bottom at a soil profile with an interval $20 \mathrm{~cm}$ in a measuring point.

$$
K f s=35.22 \times\left(0.0041 \times R_{2}-0.0054 \times R_{1}\right) \text {. }
$$

\section{Data analysis}

Microsoft Excel was employed for test data processing; 3S method in DPS software was used to exclude $K f s$ outliers of different depths of the three types of sandy land (significance level $\mathrm{p}=0.05$ ), and Shapiro-Wilk test method in the software was used for normality test of $K f s$ values; SPSS15.0 software was employed for significance test of the differences in $K f s$ of different depths among various types of sandy lands (significant level $p=0.05$ ); correlation analysis in SPSS15.0 software 
was used to analyze the correlation of $K f s$ and bulk density, organic matter, mechanical components and other physical and chemical factors of the three types of sandy land.

\section{RESULTS}

\section{Changes of some soil physical and chemical properties}

The results of analysis on soil physical and chemical properties of the three types of sandy land are shown in Table 1. It could be seen that (1) from the point of view of the average value, there was not much difference in the bulk density of the three types of sandy land; the bulk density of pine woodland and poplar woodland was higher $\left(1.54 \mathrm{~g} / \mathrm{cm}^{3}\right)$, while that of farmland was lower $(1.44$ $\left.\mathrm{g} / \mathrm{cm}^{3}\right)$. In light of different depths, the bulk density was higher at the depth of $40 \sim 60 \mathrm{~cm}$ of pine woodland and poplar woodland and $0 \sim 20 \mathrm{~cm}$ of farmland; (2) organic matter content in farmland was the highest, and the average value was $44 \mathrm{~g} / \mathrm{kg}$, because fertilization greatly increased the organic matter in farmland; the content in poplar woodland was lower, and the average value was $20 \mathrm{~g} / \mathrm{kg}$; the content in pine woodland was the lowest, and the average value was $11 \mathrm{~g} / \mathrm{kg}$. According to different soil thickness, except for poplar woodland, the organic matter content at the depth of $0-20 \mathrm{~cm}$ of the other two types of sandy land was higher than other depths, mainly because wind erosion and falling objects increased the organic matter content in topsoil; (3) analysis on the variation of the mechanical composition of the three types of sandy soil showed that the variation pattern of coarse sand content $(2 \sim 0.1 \mathrm{~mm})$ and fine sand content $(1 \sim 0.05 \mathrm{~mm})$ was "pine woodland $>$ poplar woodland $>$ farmland", and the variation pattern of silt clay content $(<0.05 \mathrm{~mm})$ was "pine woodland < poplar woodland < farmland". With the increase in the thickness of soil layer, sand (coarse sand and fine sand) content in the three types of sandy land showed a gradually decreasing trend, while silt sand content basically showed a gradually increasing trend.

Overall, physical and chemical properties of farmland were significantly different from those of pine woodland and poplar woodland, while the difference between pine woodland and poplar woodland was relatively insignificant.

Table 1. Soil physical and chemical properties at three sites.

\begin{tabular}{|c|c|c|c|c|c|c|}
\hline Site & $\begin{array}{l}\text { Soil } \\
\text { layer } \\
(\mathrm{cm})\end{array}$ & $\begin{array}{l}\text { Bulk } \\
\text { densit } \\
(\mathrm{g} \\
\left.\mathrm{cm}^{-3}\right)\end{array}$ & $\begin{array}{l}\text { Total } \\
\text { porosit } \\
(\%)\end{array}$ & \multicolumn{2}{|c|}{$\begin{array}{l}\text { Organic Soil particle size } \\
\text { matter distribution }(\%)\end{array}$} & $\begin{array}{l}\text { ize } \\
\text { o) } \\
5<0.05 \\
\text { mm }\end{array}$ \\
\hline \multirow{6}{*}{ PNW } & $0-20$ & 1.56 & 41.12 & 16.5 & 97.551 .25 & 0.55 \\
\hline & $20-40$ & 1.52 & 42.56 & 10.0 & 97.081 .57 & 0.68 \\
\hline & $40-60$ & 1.56 & 41.29 & 8.8 & 97.021 .68 & 0.68 \\
\hline & $60-80$ & 1.55 & 41.60 & 8.1 & 97.081 .35 & 0.83 \\
\hline & $80-100$ & 1.51 & 43.12 & 11.5 & 94.522 .28 & 2.28 \\
\hline & Mean & 1.54 & 41.94 & 11.0 & 96.651 .63 & 1.00 \\
\hline \multirow{6}{*}{ PW } & $0-20$ & 1.56 & 41.18 & 19.5 & 87.179 .20 & 2.95 \\
\hline & $20-40$ & 1.57 & 40.92 & 16.5 & 84.1712 .08 & 3.07 \\
\hline & $40-60$ & 1.59 & 40.06 & 18.8 & 82.1512 .58 & 4.40 \\
\hline & $60-80$ & 1.53 & 42.16 & 23.0 & 70.3020 .26 & 8.55 \\
\hline & $80-100$ & 1.45 & 45.27 & 24.1 & 61.5925 .68 & 11.78 \\
\hline & Mean & 1.54 & 41.92 & 20.4 & 77.0815 .96 & 6.15 \\
\hline \multirow{6}{*}{ FL } & $0-20$ & 1.47 & 44.45 & 51.2 & 55.9325 .64 & 17.36 \\
\hline & $20-40$ & 1.42 & 46.50 & 42.8 & 54.7222 .70 & 20.88 \\
\hline & $40-60$ & 1.45 & 45.44 & 34.3 & 45.0531 .04 & 22.54 \\
\hline & $60-80$ & 1.38 & 47.94 & 39.3 & 43.5232 .04 & 23.19 \\
\hline & $80-100$ & 1.46 & 45.06 & 49.7 & 42.2729 .23 & 26.95 \\
\hline & Mean & 1.44 & 45.88 & 43.5 & 48.3028 .13 & 22.18 \\
\hline
\end{tabular}




\section{Changes of Kfs with the type of sandy land}

In order to reduce the influence of outliers on the analysis results, $3 \mathrm{~S}$ method in DPS software (significance level $p=0.05$ ) was employed to pick out and exclude $K f s$ outliers of different depths of various types of sandy land, in which pine woodland and farmland each had two outliers, and poplar woodland had one outlier. Then the average value of $K f s$ of different depths of the three types of sandy land was selected, and Shapiro-Wilk test method in DPS software was used for normality test of $K f s$ of the three types of sandy land. The results showed that $K f s$ of different depths of the three types of sandy land obeyed lognormal normal distribution, consistent with relevant research results (Mohanty et al. 1994).

Analysis on the statistical characteristics of $K f s$ at different soil layers of the three types of sandy land showed (Table 2) that the mean value of $K f s$ at five soil layers of pine woodland was the highest with an average of $3.99 \mathrm{~mm} / \mathrm{min}$, followed by that of poplar woodland with an average of $2.60 \mathrm{~mm} / \mathrm{min}$, and that of farmland was the lowest with an average of $0.93 \mathrm{~mm} / \mathrm{min}$. Mean value of the standard error of $K f s$ at different soil layers of the three types of sandy land was the highest in pine woodland at 0.45 , lower in poplar woodland at 0.32 , and the lowest in farmland at 0.21 . In other words, the greater $K f s$ of the three types of sandy land, the greater their standard error. The coefficients of variation of $K f s$ of the three types of sandy land were all lower than 1, which belonged to medium variation. Mean value of the skewness at different soil layers of the three types of sandy land was higher in pine woodland and farmland at 0.84 and 0.85 , respectively, and that of poplar woodland was lower at 0.73 ; Kurtosis mean values of $K f s$ of pine woodland and poplar woodland were both positive, but the former was higher than the latter, while the Kurtosis mean value of farmland was negative, mainly because the soil physical and chemical properties of farmland (Table 1) were significantly different from those of the other two types of sandy land.

Table 2. Statistical characteristic of $K f s$ at three sites.

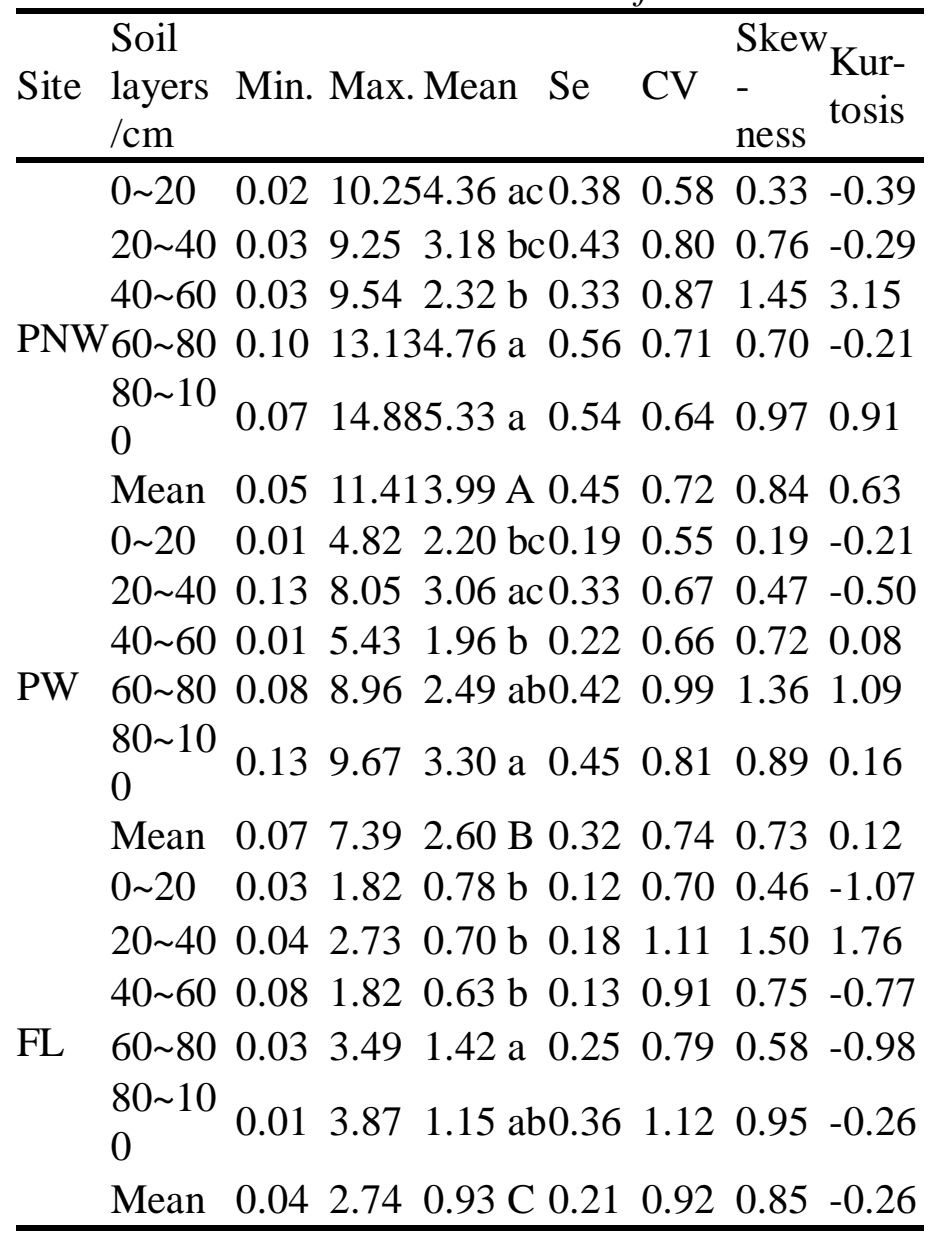


Note: The different capital letter is meaning statistically significant differences between sites $(\mathrm{p}<0.05)$. The different little letter is meaning statistically significant differences between layers at a site.

\section{Kfs with soil depths}

Table 2 also shows $K f s$ variation with the type of sandy land and the depth of soil layer and the difference significance test results. It could be seen that the difference in $K f$ s among different sandy lands was significant $(\mathrm{p}<0.05)$, suggesting that different land use types had a significant impact on $K f s$. (1) It could be seen from $K f s$ variation of each type of sandy land with the depth of soil layer that $K f s$ of pine woodland decreased first and then increased with increasing depth, showing a V type trend; the minimum and maximum values were obtained at the depth of 40 60 cm and 80 100 $\mathrm{cm}$, respectively. $K f s$ of poplar woodland increased first, then decreased and increased again with increasing depth, and the minimum and maximum values were obtained at the depth of $40 \sim 60 \mathrm{~cm}$ and $80 \sim 100 \mathrm{~cm}$, respectively. With increasing depth, $K f s$ of farmland decreased first, then increased and decreased again, just the opposite of that of poplar woodland, and the minimum and maximum values were obtained at the depth of $40 \sim 60 \mathrm{~cm}$ and $60 \sim 80 \mathrm{~cm}$, respectively. Overall, $K f s$ at the depth of 40 60 $\mathrm{cm}$ of the three types of sandy sand was basically lower than that in other depths, and this layer became an aquitard. (2) Analysis on the difference in $K f s$ of different depths of each type of sandy land showed that except $K f s$ at the depth of $20 \sim 40 \mathrm{~cm}, K f s$ of pine woodland at the depth of $40 \sim 60 \mathrm{~cm}$ was significantly different from the other four soil layers; there were considerable differences between $20 \sim 40 \mathrm{~cm}$ and $60 \sim 80 \mathrm{~cm} \& 80 \sim 100 \mathrm{~cm}$, but there were no significant differences among $0 \sim 20 \mathrm{~cm}, 60 \sim 80 \mathrm{~cm}$ and $80 \sim 100 \mathrm{~cm}$. Kfs of poplar woodland at the depth of 40-60 cm was significantly different from $20 \sim 40 \mathrm{~cm}$ and $80 \sim 100 \mathrm{~cm}$; there were high differences between 80 100 cm and 0 20 cm \& 40 60 cm, while there were no large differences among the remaining soil layers. $K f s$ of farmland at the depth of $60 \sim 80 \mathrm{~cm}$ was significantly different from $0 \sim 20 \mathrm{~cm}, 20 \sim 40 \mathrm{~cm}$ and $40 \sim 60 \mathrm{~cm}$, while differences among the remaining soil layers were not significant.

The changes of $K f s$ with different depths in PNW can be fitted by parabola model. The equations was

$$
K f s=0.4851 \mathrm{x}^{2}-2.5573 \mathrm{x}+6.3258, \mathrm{R}^{2}=0.7591 .(2)
$$

where $x$ present soil depth $(20,40,60,80,100 \mathrm{~cm})$.

But the changes of $K f s$ with different soil layers for PW and FL were complex and may not be fitted by any model.

Generally, the changes of $K f s$ with soil depth were different of each other for different sandy land.

\section{Relationship of Kfs with soil physical and chemical properties}

Existing studie (Shan et al. 1998) have shown that $K f s$ has a good correlation with soil bulk density, organic matter content and structure. It was found through analysis on the correlation of $K f s$ and soil physical and chemical properties of the three types of sandy land (Table 3) that $K f s$ of pine woodland, poplar woodland and farmland was significantly positively correlated with soil bulk density $(p<0.05)$, and extremely significantly positively correlated with coarse sand component $(2 \sim 0.1 \mathrm{~mm})$, while extremely significantly negatively correlated with organic matter content, fine sand component $(0.1 \sim 0.05 \mathrm{~mm})$ and silt clay component $(<0.05 \mathrm{~mm})$. That is to say, $K f s$ of pine woodland, poplar woodland and farmland in Horqin Sandy Land is significantly affected by the organic matter content and soil mechanical composition, and then by bulk density. Specifically, the higher coarse sand component and bulk density of the soil, the greater $K f s$; the higher fine sand and silt clay components and organic matter content, the smaller $K f s$, which is consistent with the existing research results (Yao et al. 2013(b)). 
Table 3. Correlation of $K f s$ and soil physical and chemical properties.

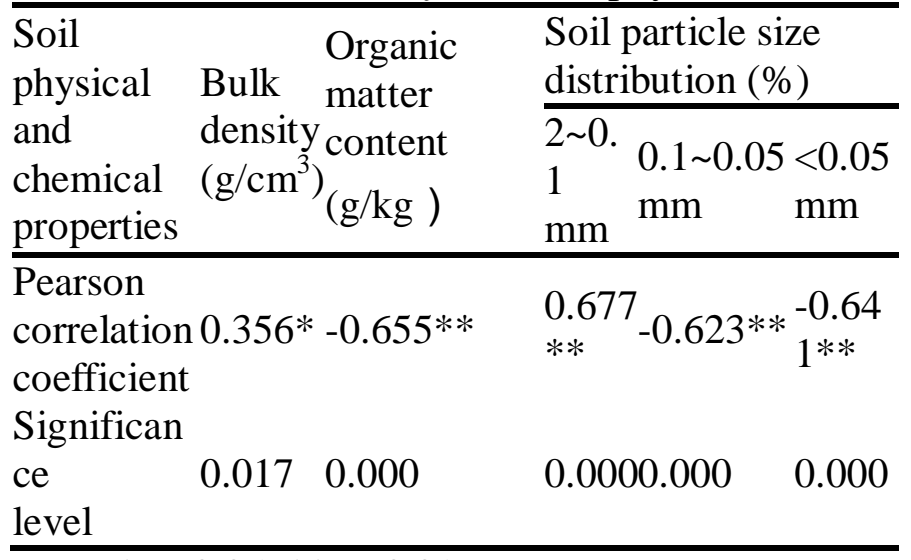

Note: $* \mathrm{p}<0.05 ; * * \mathrm{p}<0.01$

\section{CONCLUSIONS}

$K f s$ of pine woodland, poplar woodland and farmland in Horqin Sandy Land differ significantly $(p<0.05)$, and the average values at different soil layers are $3.99 \mathrm{~mm} / \mathrm{min}, 2.60 \mathrm{~mm} / \mathrm{min}$ and 0.93 $\mathrm{mm} / \mathrm{min}$;

The variation pattern of $K f s$ of the three types of sandy land varies - the variation of $K f s$ of pine woodland constitutes a parabola with changes in depth, while there is no regular pattern for the variation of $K f s$ of poplar woodland and farmland with changes in depth; the $K f s$ of the three types of sandy land at the depth of $40 \sim 60 \mathrm{~cm}$ is basically lower than other depths, this layer becomes an aquitard, and there are significant differences among partial soil layers;

$K f s$ of the three types of sandy land is significantly affected by organic matter content and soil mechanical composition, followed by bulk density. Besides, $K f s$ increases with the increase in coarse sand component and bulk density, while decreases with the increase of soil fine sand and silt clay component and organic matter content.

\section{ACKNOWLEDGEMENTS}

We really appreciate to Miss J.Y. Yun for her warmhearted help in field work. This study was supported by the National Natural Science Foundation of China (No. 31300388; No. 41361013); Dr. Start-up Science Research Foundation of Lanzhou City University (No. LZCU-BS2013-09; No. LZCU-BS2013-12); Research Foundation of university in Gansu Province (No. 2013B-074) and Chancellor Research and Innovation Fund of Lanzhou City University (No. LZCU-XZ2014-12).

\section{REFERENCES}

[1] Amoozegar, A. 1989. A compact constant-head permeameter for measuring saturated hydraulic conductivity of the vadose zone. Soil Science Society of American Journal, 53(5): 1356-1361.

[2] Fares, A., Aiva, A.K. \& Nkedi-Kizza, P. 2000. Estimation of soil hydraulic properties of a sandy soil using capacitance probes and Guelph permeameter. Soil science, 165 (10): 768 -777.

[3] Hu, W., Shao, M.A., Wang, Q.J., et al. 2005. Effects of sampling size on measurements of soil saturated hydraulic conductivity. Acta pedologica sinica, 42(6): 1040-1043 (In Chinese with English Abstract).

[4] Institute of Soil Sciences. 1978. The Chinese Academy of Sciences. Physical and Chemical Analysis Methods of Soils (in Chinese). Shanghai: Shanghai Science and Technology Press, 7-59 (In Chinese with English Abstract).

[5] Liang, X.F., Zhao, S.W., Zhang, Y. et al. 2009. Effects of vegetation rehabilitation on soil saturated hydraulic conductivity in Ziwuling Forest Area (in Chinese). Acta Ecologica Sinica, 29(2): 636-642 (In Chinese with English Abstract). 
[6] Mohanty, B.P., Kanwar, R.S. \& Everts, C.J. 1994. Comparison of Saturated Hydraulic Conductivity Measurement Methods for a Glacial-Till Soil. Soil Science Society of America Journal, 58(3):672-677.

[7] Niu, H.S., Ii, X.Z. \& Chen, Z.Z. 1999. Effeets of Stocking Rateon Soil Saturated Hydraulie Conductivity and Its Spatial Variation. Acta agrestia sinica, 7(3): 211-216 (In Chinese with English Abstract).

[8] Price, K., Jackson, C.R. \& Parker, A.J. 2010. Variation of surficial soil hydraulic properties across land uses in the southern Blue Ridge Mountains, North Carolina, USA. Journal of hydrology, 383(3/4): 256-268.

[9] Shan, X.Z., Wei, Y.Q., Yan, H.J., et al. 1998. I nfluence of organic matter content on s oil hydr odynamic parameters . Acta Pedologica Sinica, 35(1):1-9 (In Chinese with English Abstract).

[10] Su, P.S. 2000. Research on Soil Dynamic Constants of Sandy Land. Journal of desert research, 20(3) : 329- 332 (In Chinese with English Abstract).

[11] Tietje, O. \& Hennings, V. 1996. Accuracy of the saturated hydraulic conductivity prediction by pedo-transfer functions compared to the variability within FAO textural classes. Geoderma, 69(1/2): 71-84.

[12] Yao, S.X., Zhang, T.H., Zhao, C.C., et al. 2013(a). Saturated hydraulic conductivity of soils in the Horqin Sand Land of Inner Mongolia, northern China. Environmental Monitoring and Assessment, 185(7), 6013-6021.

[13] Yao, S.X., Zhang, T.H., Zhao, C.C., et al. 2013(b). A comparison of soil saturated hydraulic conductivity $(K F S)$ in different Horqin Sand Land. Acta pedologica Sinica, 50(3):45-53 (In Chinese with English Abstract).

[14]Zhao, P.P., Shao, M.A. \& Wang, T.J. 2009. Spatial distributions of soil surface-layer saturated hydraulic conductivity and controlling factors on Dam Farmlands. Water Resources Management, 24(10): 2247-2266.

[15]Zheng, J.Y., Shao, M.A. \& Zhang, X.C. 2004. Spatial Variation of Surface Soil s Bulk Density and Saturated Hydraulic Conductivity on Slope in Loess Region. Journal of Soil and Water Conservation, 18(3): 53-56 (In Chinese with English Abstract). 